\title{
IMPACT RESPONSES OF PRESTRESSING TENDONS IN RAILWAY CONCRETE SLEEPERS IN HIGH SPEED RAIL ENVIRONMENTS
}

\author{
Sakdirat Kaewunruen ${ }^{1}$ and Alex M. Remennikov ${ }^{2}$ \\ ${ }^{1}$ Birmingham Centre for Railway Research and Education, School of Civil Engineering \\ The University of Birmingham, Edgbaston, B15 2TT UK \\ e-mail: s.kaewunruen@bham.ac.uk \\ ${ }^{2}$ School of Civil, Mining, and Environmental Engineering \\ University of Wollongong, Northfield Ave, Wollongong, NSW 2522 Australia \\ e-mail: alexrem@uow.edu.au
}

Keywords: Railway, Concrete Sleepers, Railroad Ties, Prestressing Tendons/Wires, Impact Analysis, Dynamic Responses, LS-Dyna.

\begin{abstract}
Prestressed concrete sleepers (or railroad ties) are designed in order to carry and transfer the wheel loads from the rails to the ground and are installed as the crosstie beam support in railway track systems. They are subjected to impact loading conditions that are resulted from train operations over wheel or rail abnormalities, such as flat wheels, dipped rails, crossing transfers, rail squats, corrugation, etc. The magnitude of the shock load relies on various factors such as axle load, types of wheel/rail imperfections, speeds of vehicle, track stiffness, etc.
\end{abstract}

This paper demonstrates the development of finite element modelling to evaluate the dynamic responses of prestressed tendons or wires embedded in concrete sleepers, particularly under a variety of impact loads. The force prediction under high speed rail environment was conducted using D-TRACK. The 3D finite element model of prestressed concrete sleeper has been developed using a finite element package, LS-Dyna. It has been verified by the experiments carried out using the high capacity drop-weight impact machine at the University of Wollongong, Australia. The experimental results provide very good correlation with numerical simulations. In this paper, the numerical studies are extended to evaluate the dynamic behaviors of high strength steel wires and their responses under different parameters in high speed rail environments. The outcome of this study can potentially lead to the dynamic design guideline for prestressed concrete sleepers under low-cycle fatigues. Future work includes more detailed investigation into the effect of track bed and rail pad degradation subject to higher frequency impacts. 


\section{INTRODUCTION}

For ballasted tracks worldwide, railway sleeper is a major component to redistribute train axle loads from the rails to the underlying ballast supporting system. Typical ballasted railway track and its components can be seen in Figure 1 [1]. It has been chronically believed based on the industry practice that railway concrete sleepers possess reserved strength that are untapped. Accordingly, it is crucial to evaluate the spectrum and amplitudes of forces applied to the railway track, in order to understand more clearly the behaviors in which track components respond to those forces, and to identify the processes whereby concrete sleepers in particular carry those force actions. Recent findings show that the nature of the majority of loading conditions on track structures is of dynamic impact [2]. Those loads are normally of short duration but of very high magnitude. They are ascribed to the wheel/rail interactions associated with irregularities, i.e. wheel burns, wheel flats, corrugations, non-uniform track modulus, and any other out-of-round wheel defects. Structural performance monitoring is an effective way to establish better understanding into the impact behaviors of prestressed concrete sleepers.

In addition, cracks in concrete sleepers have been visually observed by many railway organizations. As described in the review [3], the principal cause of cracking is the infrequent but high-magnitude wheel loads produced by a small percentage of "bad" wheels or railhead surface defects. For instance, the typical loading duration produced by wheel flats is about 1$10 \mathrm{msec}$, while the force magnitude can be over $400 \mathrm{kN}$ per rail seat. Existing structural design concept for prestressed concrete sleepers in Australia is based on permissible stress principle taking into account only the static and quasi-static loads, which are unrealistic to the actual dynamic loads on tracks. However, it is inevitable to avoid those criteria in any consideration of rail track designs since even the standard quality ride of rail vehicles still involves with the low-velocity impact forces. In order to devise a new limit states design concept whereas the extreme loading conditions can be taken into account, the research efforts are required to perform comprehensive studies of the loading conditions, the static behaviour, the dynamic response, and the impact resistance of the prestressed concrete sleepers [4]. A major research task at the University of Wollongong is to evaluate the dynamic responses of concrete sleepers under static and impact loads. There have been only a few studies related to the modelling of prestressed concrete sleepers. Most of them predicted the rail seat flexural behaviour of the concrete sleepers [5-6]. Also, since high-capacity impact tests require significant amount of resources and are time consuming, a suitable way to develop an understanding of the impact behaviour is to use the numerical impact simulations.

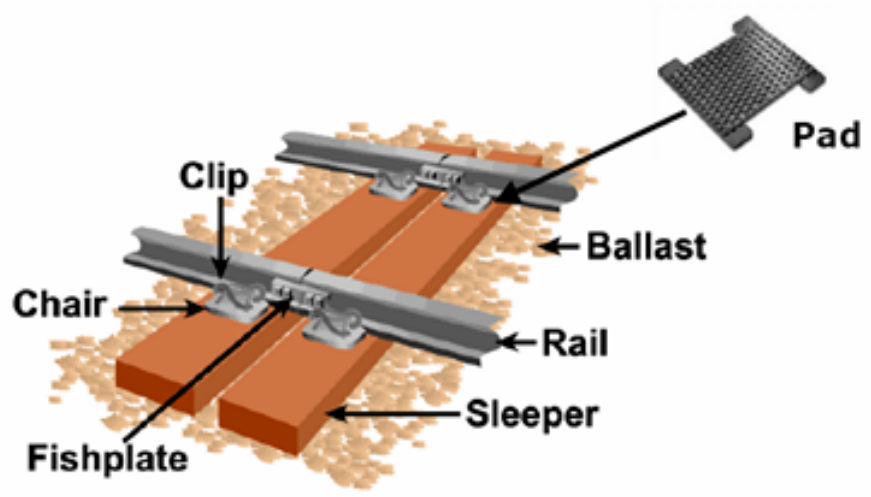

Figure 1 Typical ballasted railway track and its components [1] 
Finite element analysis (FEA) provides a tool that can simulate and predict the responses of reinforced and prestressed concrete members. A three-dimensional non-linear finite element model of a railway prestressed concrete sleeper for static analysis was developed using the general purpose finite element analysis package, ANSYS10 [7]. The concrete section was modelled using SOLID65 solid element where the compressive crushing of concrete and the concrete cracking in tension zone can be accommodated. In the current practice, the railway concrete sleeper is designed to resist prestressing force fully throughout the whole cross section as the force/moment redistribution can be seen in Figure 2. This makes the smeared crack analogy unsuitable for the replacement of prestressing tendons in the fully prestressed concrete sleeper. The use of a truss element, LINK8, for discrete reinforcement modelling, is then more practicable. An initial strain real-constant feature in ANSYS appropriately substituted the pre-tensioning forces in the tendon elements. However, it was assumed that perfect bonding between concrete and pre-stressing wires. The static full-scale experiment was conducted to validate this FE model [7]. The experimental details were based on the associated Australian Standards $[8,9]$.

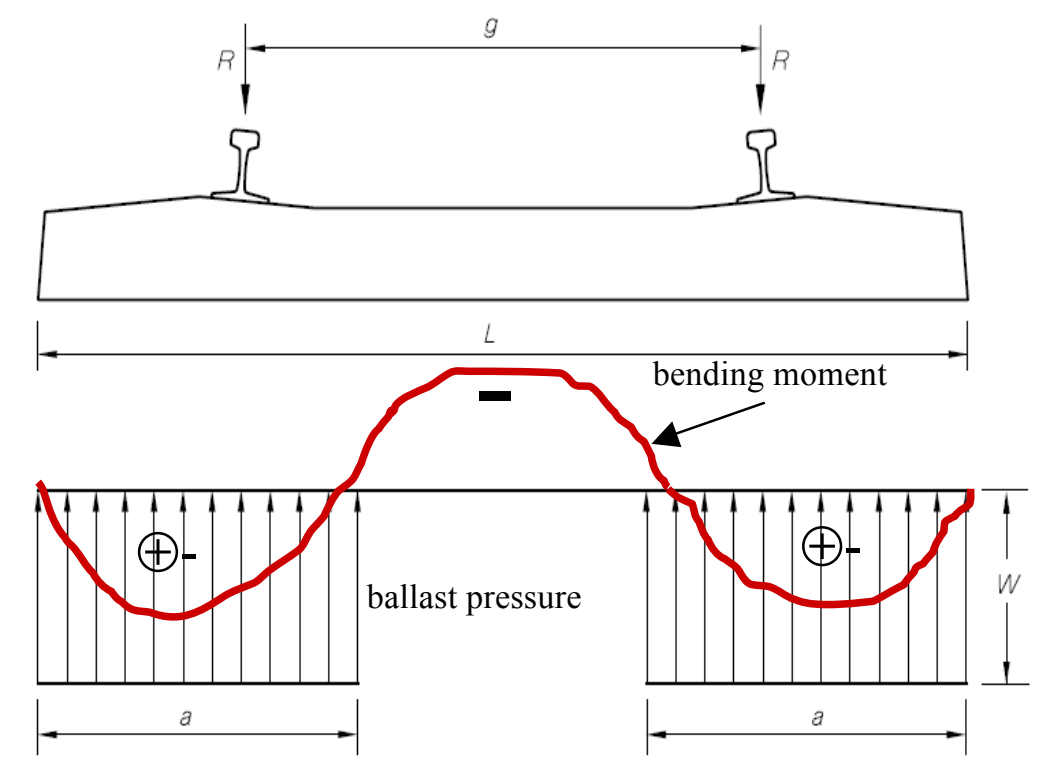

Figure 2 Moment distribution for standard gauge sleepers (8)

The calibrated finite element model has been extended to include ballast support and in situ boundary conditions. The extended model was linked to LS-Dyna [10] for impact analysis and validation against the drop impact tests. This paper investigates the impact responses of pre-stressing tendons in prestressed concrete sleepers and compares such the results with experimental data obtained from the drop impact machine, which are equivalent to the peak dynamic forces ranging from $200-1,700 \mathrm{kN}$. The highlights in this paper are the better understandings into the influence of track components particularly the ballast support and train speeds, which can be simulated by impulse duration, on the behavior of railway prestressed concrete sleepers.

\section{THREE DIMENSIONAL FINITE ELEMENT MODEL}

In this study, the concrete part of the sleeper was modelled using a three-dimensional solid element, which has the material model to predict the failure of brittle materials [7]. This ele- 
ment is defined with eight nodes - each with three degrees of freedom: translations in nodal $\mathrm{x}$, $\mathrm{y}$, and $\mathrm{z}$ directions. To simulate the behaviour of prestressing wires, a truss element, were used to withstand the initial strain attributed to prestressing forces, by assuming perfect bond between these elements and concrete. Note that this truss element cannot resist neither bending moments nor shear forces. Non-linear elastic behaviour of concrete can alternatively be defined by the multi-linear stress-strain relationships. The modulus of elasticity of concrete $\left(E_{c}\right)$ can be found based on AS3600 [11] using the compressive strength of $88 \mathrm{MPa}$.

For prestressing wires, the bi-linear elasto-plastic material models can be used as well as the multi-linear isotropic model from the manufacturer's data. The $0.2 \%$ proof stress is 1,700 $\mathrm{MPa}$ and the ultimate stress is $1,930 \mathrm{MPa}$. The static and dynamic elasticity of moduli of prestressing wire are 190,000 MPa.

The multi-linear isotropic dynamic stress-strain curve for the concrete and prestressing wires can be calculated based on the consideration of the effect of strain rate. Based on the assumption of perfect bond between prestressing wires and concrete, the dynamic material properties of concrete and prestressing wires can be determined as follows [12].

\section{Concrete:}

$$
\begin{aligned}
& \sigma=f_{c, d y n}^{\prime}\left[2 \frac{\varepsilon}{\varepsilon_{c 0, d y n}}-\left(\frac{\varepsilon}{\varepsilon_{c 0, d y n}}\right)^{2}\right] \\
& \frac{f_{c, d y n}^{\prime}}{f_{c, s t}^{\prime}}=1.49+0.268 \log _{10} \dot{\varepsilon}+0.035\left[\log _{10} \dot{\varepsilon}\right]^{2} \\
& \frac{\varepsilon_{c 0, d y n}}{\varepsilon_{c 0, s t}}=1.24+0.053 \log _{10} \dot{\varepsilon}
\end{aligned}
$$

where $\sigma$ is the dynamic stress, $f_{c, d y n}^{\prime}$ is the dynamic compressive strength, $f_{c, s t}^{\prime}$ is the static compressive strength of concrete, $\varepsilon$ is the dynamic strain, $\varepsilon_{c 0, s t}$ is the static ultimate strain, and $\dot{\varepsilon}$ is the strain rate in concrete fibre.

Prestressing wires:

$$
\frac{f_{y, d y n}}{f_{y, s t}}=10^{0.38 \log _{10} \dot{\varepsilon}^{-0.258}}+0.993
$$

where $f_{y, d y n}$ is the dynamic upper yield point stress, $f_{c, s t}{ }^{\prime}$ is the static upper yield point stress of prestressing wires (about 0.84 times proof stress), and $\dot{\varepsilon}$ is the strain rate in tendon.

A three-dimensional model of a typical railway prestressed concrete sleeper was developed initially in ANSYS [7] as illustrated in Figure 3. The dedicated solid bricks represent the concrete and the embedded three-dimensional spar elements are used as the prestressing wires. The pre-tensioning was modelled using an initial strain in the tendons corresponding to the prestressing forces at final stage (sustained prestressing force after all losses). For impact 
simulations, a FE model was extended to include rails, rail pads, ballast bed, and falling mass, as shown is Figure 4. The extended finite element model was calibrated using vibration data [13-16]. The updated finite element model was then transferred to LS-Dyna. The simulation results were achieved by assigning the initial velocity to the drop mass to generate an impact event, similarly to the actual drop tests.
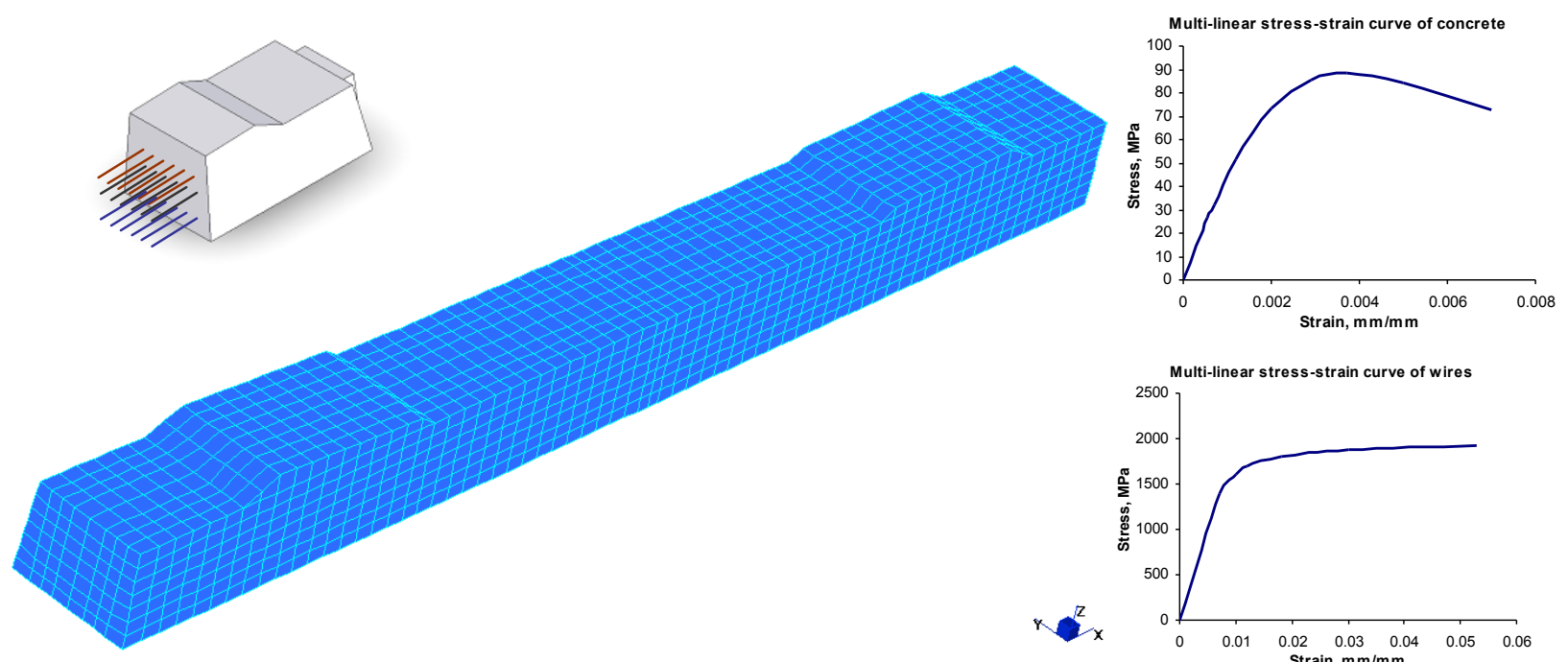

Figure 3 A three-dimensional model of railway sleeper [4]

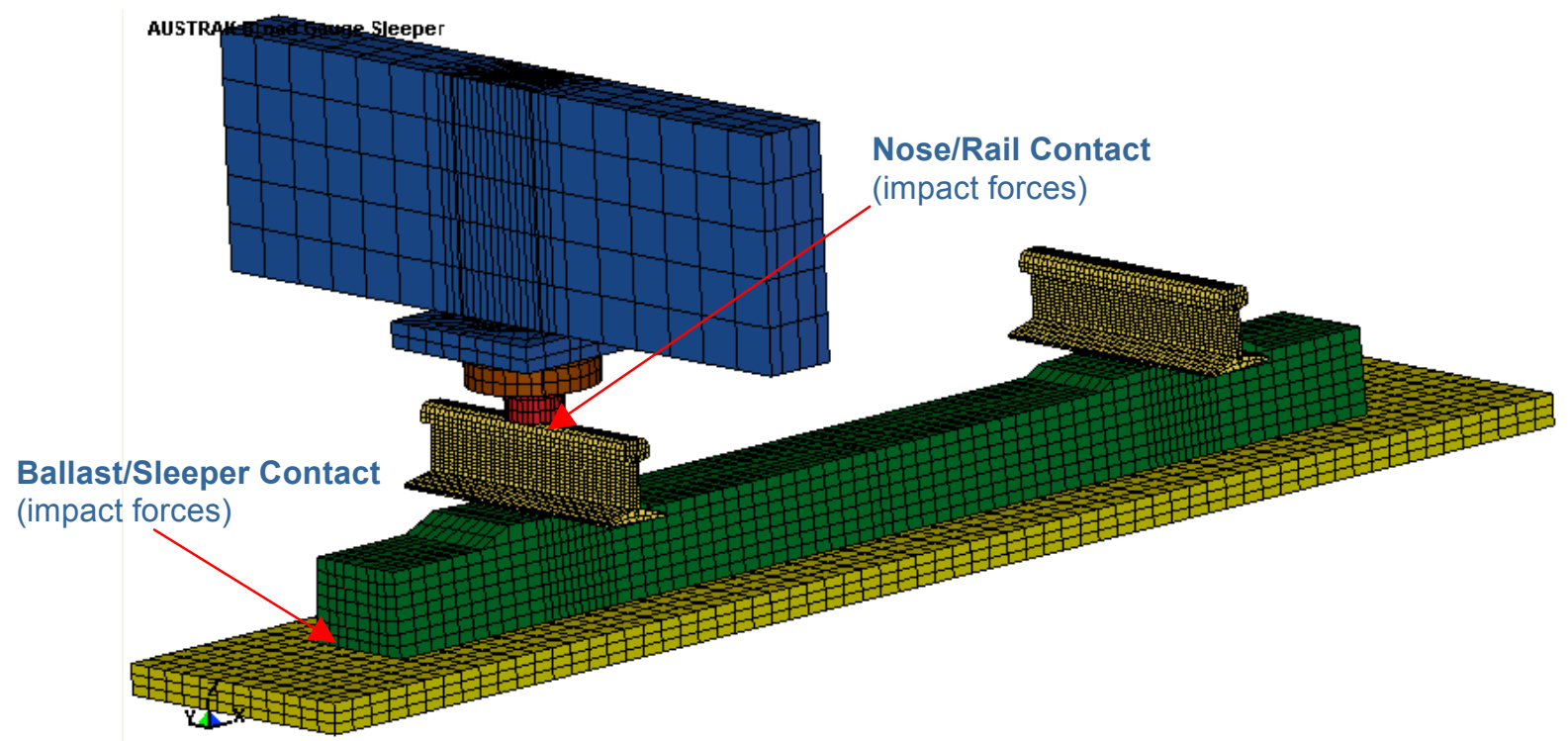

Figure 4 Extended finite element model of railway sleeper [4]

\section{EXPERIMENT AND FINITE ELEMENT MODEL VALIDATION}

The prestressed concrete sleepers used in this study were kindly supplied by an Australian manufacturer, under a collaborative research project of the Australian Cooperative Research Centre for Railway Engineering and Technologies (Rail CRC). A series of static tests on the concrete sleepers was performed in accordance with the Australian Standards. The details of static responses, rotational capacity, post-failure mechanism, and residual load-carrying capacity of the prestressed concrete sleeper can be found in ref: [17]. 


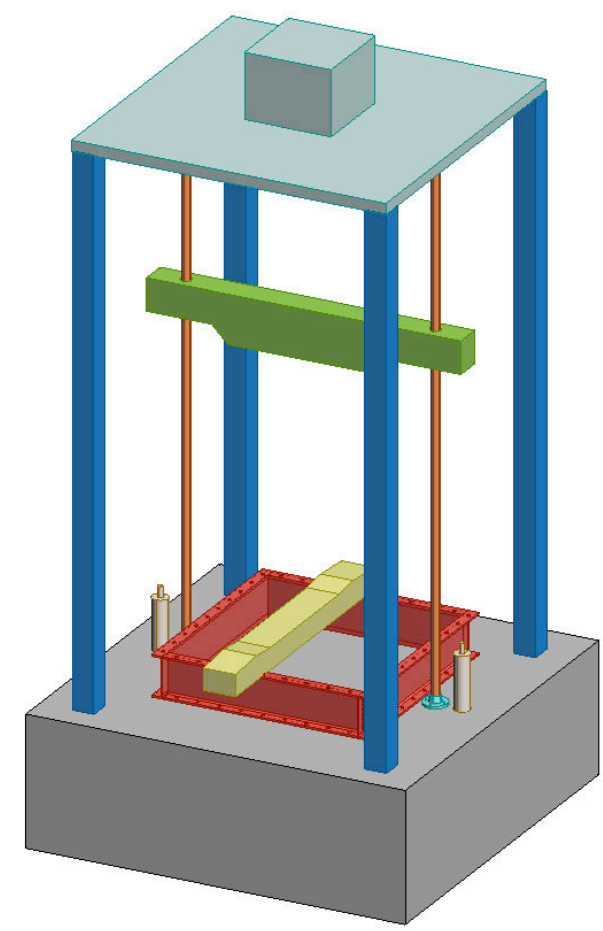

a) sketch of impact machine

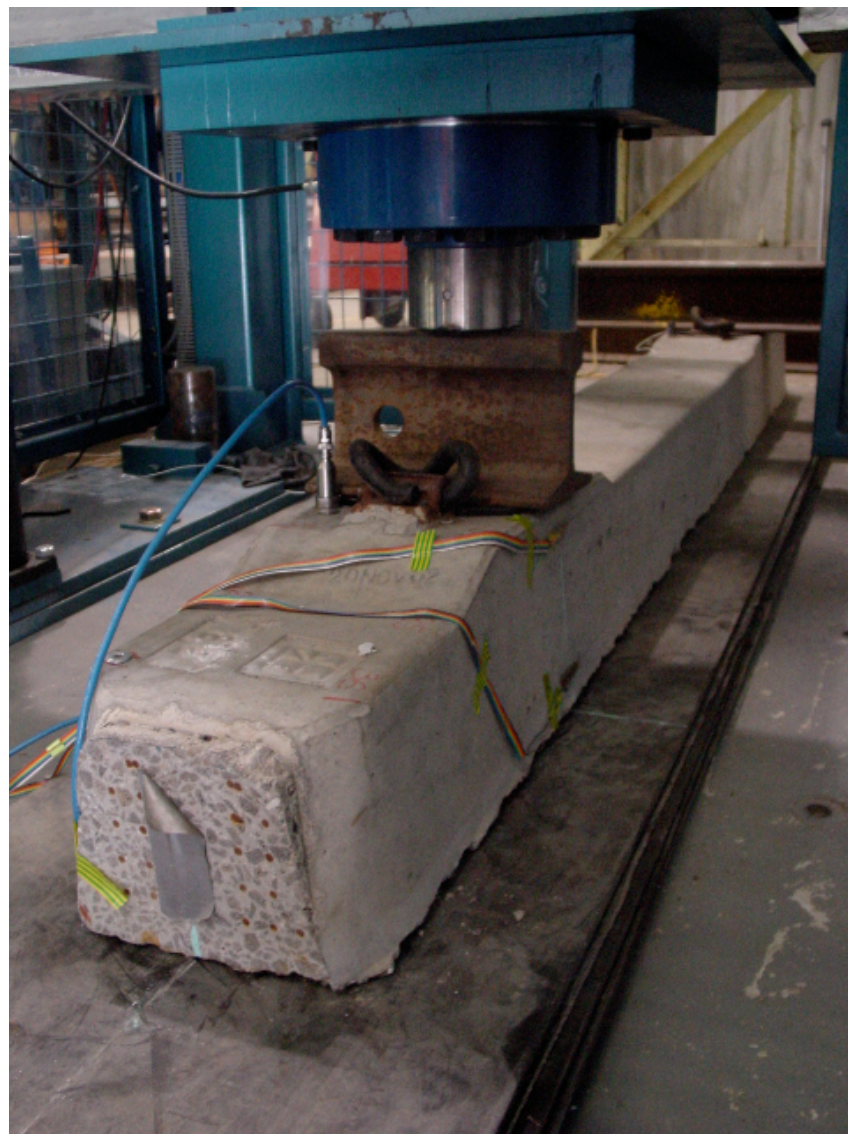

b) impact test setup

Figure 5 Experimental overview 
A new high-capacity drop-weight impact testing machine has been developed at the University of Wollongong, as depicted in Figure 5a. The drop mass assembled is $5.81 \mathrm{kN}$ with the varied height from 0 to $6 \mathrm{~m}$ in total, which provide the maximum capacity of $10 \mathrm{~m} / \mathrm{s}$ drop velocities. Experimental setup and impact tests were arranged in accordance with the Australian Standards, as shown in Figure 5b. The accelerometers have been used to measure the dynamic responses at mid-span and railseat. The contact impact force between impactor and rail was recorded using the dynamic load cell connected to the data acquisition system. For the verification purpose, the drop height used was $0.1 \mathrm{~m}$ since there was the measurement limitation for the accelerometers employed. The in-situ conditions of railway concrete sleeper were replicated. Attempts to simulate impact loading actually occurred in tracks were succeeded experimentally and numerically. Comparison between numerical and experimental results can be found in Figure 6. It is found that the finite element model is fairly sufficient for use in predicting impact responses of the prestressed concrete sleepers. The trends of peak acceleration responses are quite close to each other, although there is certain phase difference.

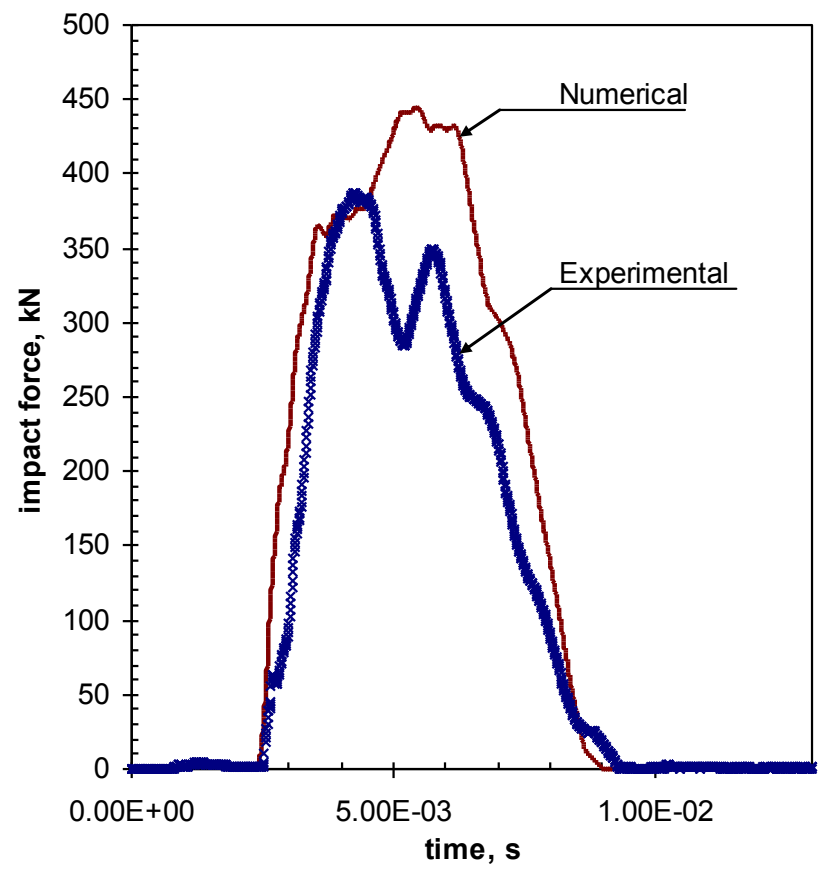

a) contact shock load
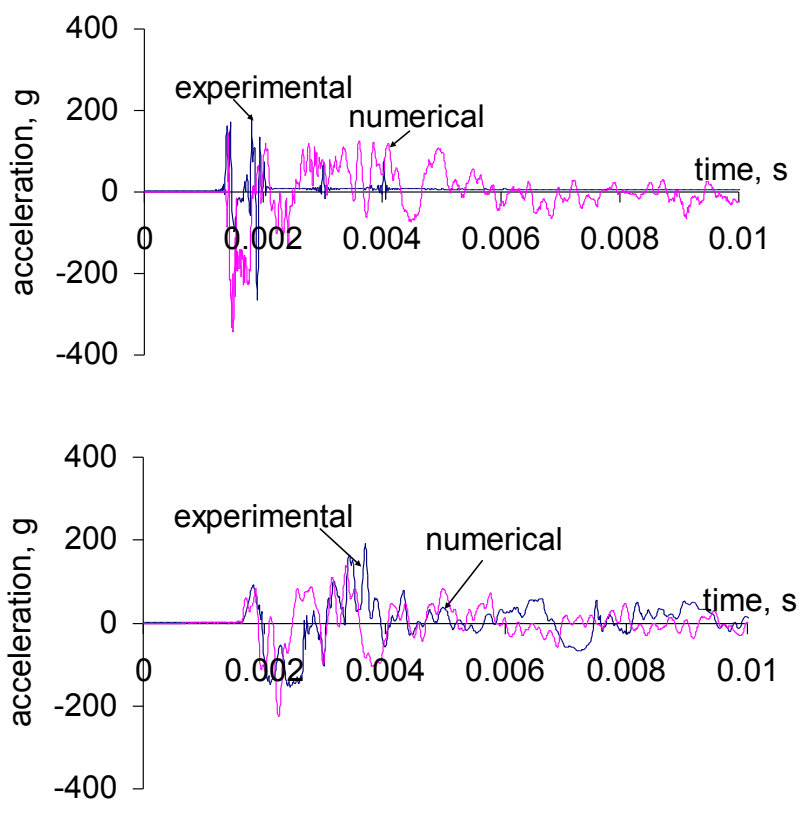

b) at railseat (top); at mid-span (bottom)

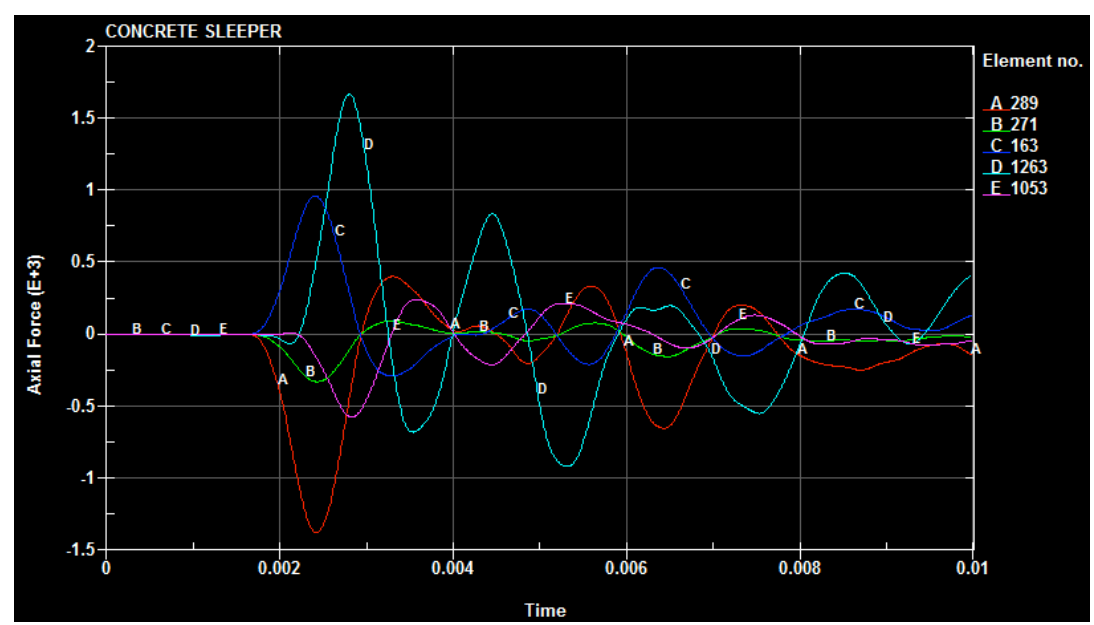

c) an example of prestressing force (at impact velocity $3 \mathrm{~m} / \mathrm{s}$ )

Figure 6 Comparison of numerical and experimental results 


\section{EFFECT OF TRACK ENVIRONMENTS}

In general, the main track components that require maintenance or renewal apart from the sleeper itself include the ballast bed and rail pads. The ballast bed requires re-packing and tamping every six months or a year depending on the characteristics of gravels used at particular locations. It degrades through the breakage of gravel, resulting in the large settlement of railway tracks [16-20]. Rail pads deteriorate through the age of use. Based on this understanding, the parametric studies have been conducted and highlighted in this paper.

In the impact analysis, the drop velocity is also varied to evaluate the effect of drop heights on the impact force occurring on railway track structures. On the other hand, this analysis provides the insight into the effect of railway track environments on the contact impact forces due to the identical causes and the responses of concrete sleepers to such loading. For example, a wheel, with $10 \mathrm{~mm}$ wheel flat on a specific vehicle and running at $300 \mathrm{~km} / \mathrm{hr}$, generates different contact impact forces on tracks with different environments. However, this study focuses only on ballast and rail pad parameters as they play key role on the interface impact force characteristics and axial responses of pre-stressing tendon as illustrated below.

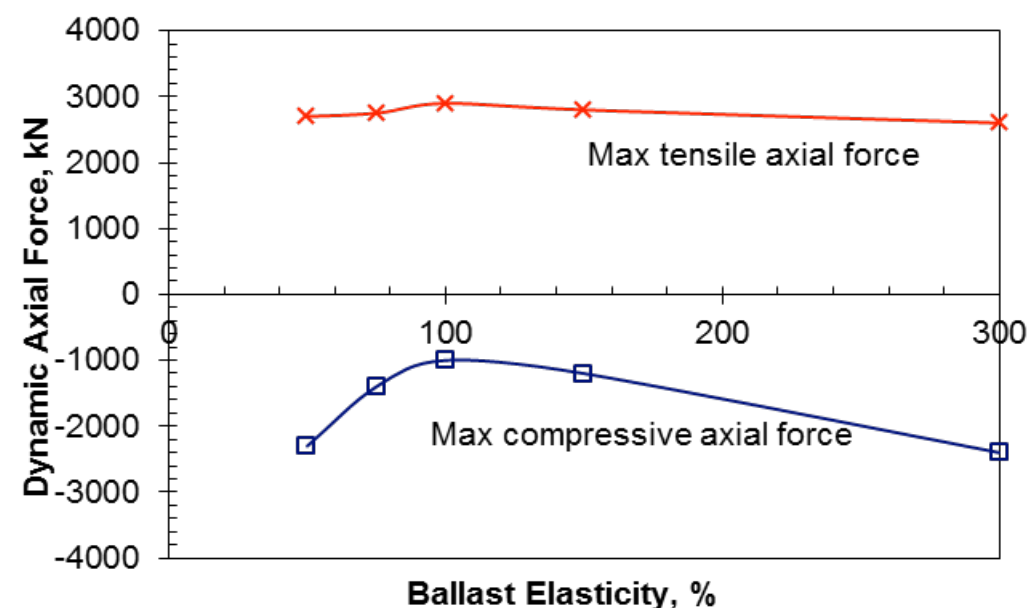

a) Axial force (ballast stiffness as percentage of original value)

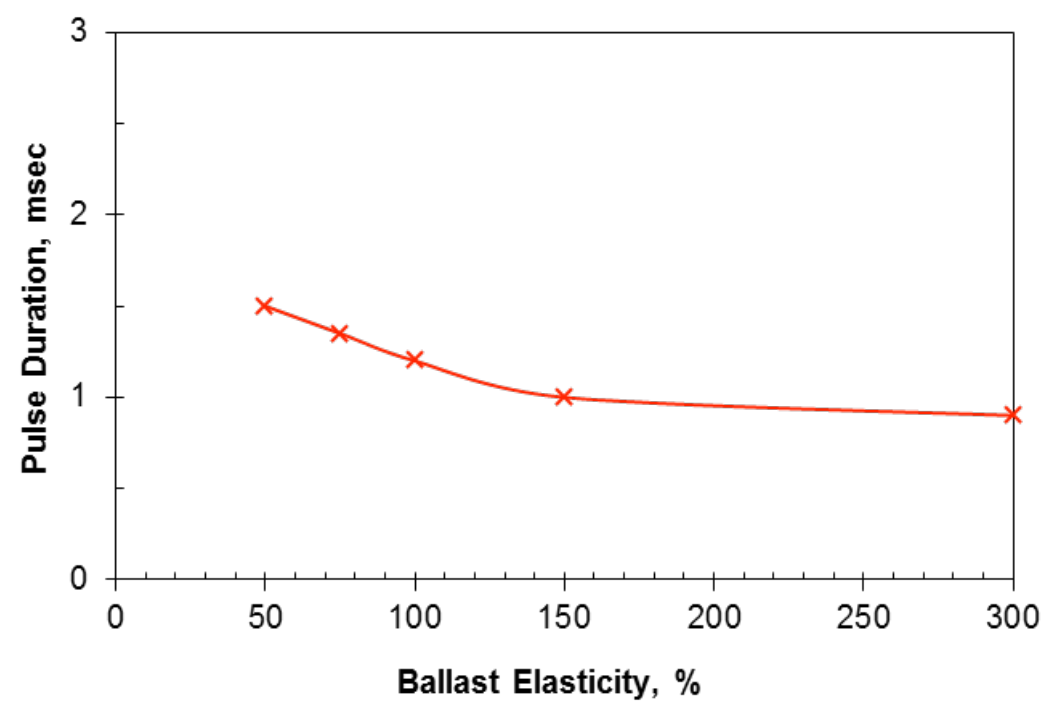

b) Pulse duration

Figure 7 Influence of ballast elasticity on axial forces of prestressing tendons 


\section{EFFECT OF DROP VELOCITIES (TRAIN SPEEDS)}

High speed trains often generate high frequency impact loading when they experience either wheel or rail abnormalities such as out-of-round wheel, wheel flats, rail squats, rail surface defects, rail joints and so on. In general, the high speed trains are designed to have light weights (around 12 to 14ton axle loads) in order to efficiently travel at high speeds. As a result, the magnitude of impact loads is somewhat similar to those in heavy rail operations. However, the effect of high speeds often results in higher-frequency impacts (i.e. shorter duration of impact forces). In this study, the effect of short duration impact (which can be simulated by increasing drop impact velocity in the numerical model) has been investigated. Figure 8 shows some results of the maximum positive and negative axial forces in prestressing tendons. In this study, the weight of impact mass is maintained constant to investigate impulsive effect due to larger magnitude but shorter duration of dynamic forces. In the future, the drop impact mass will be modified to evaluate the parametric study of impulse duration.

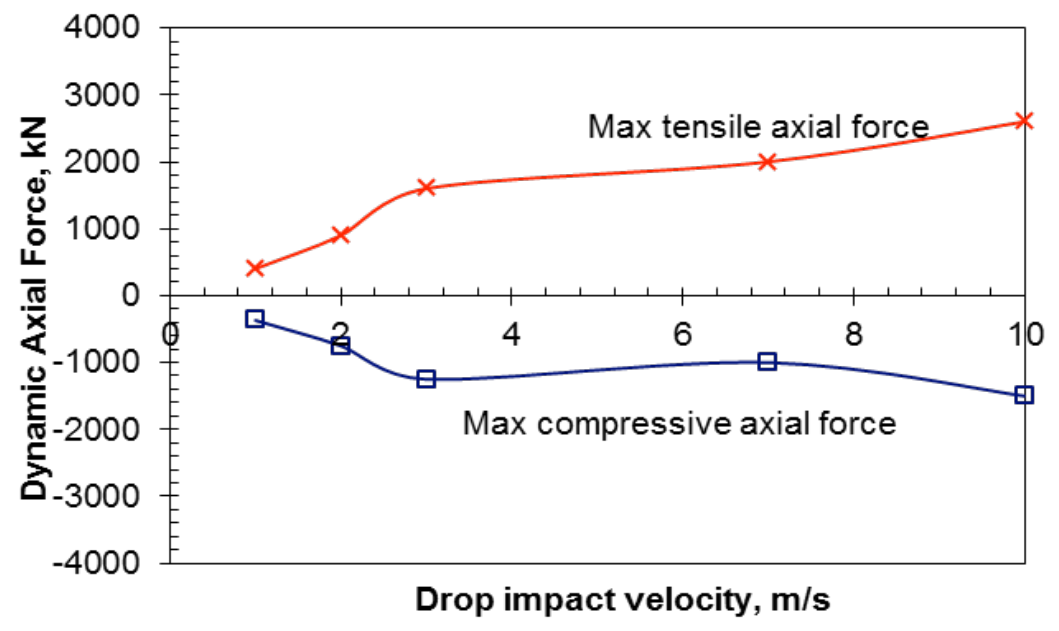

a) Axial force

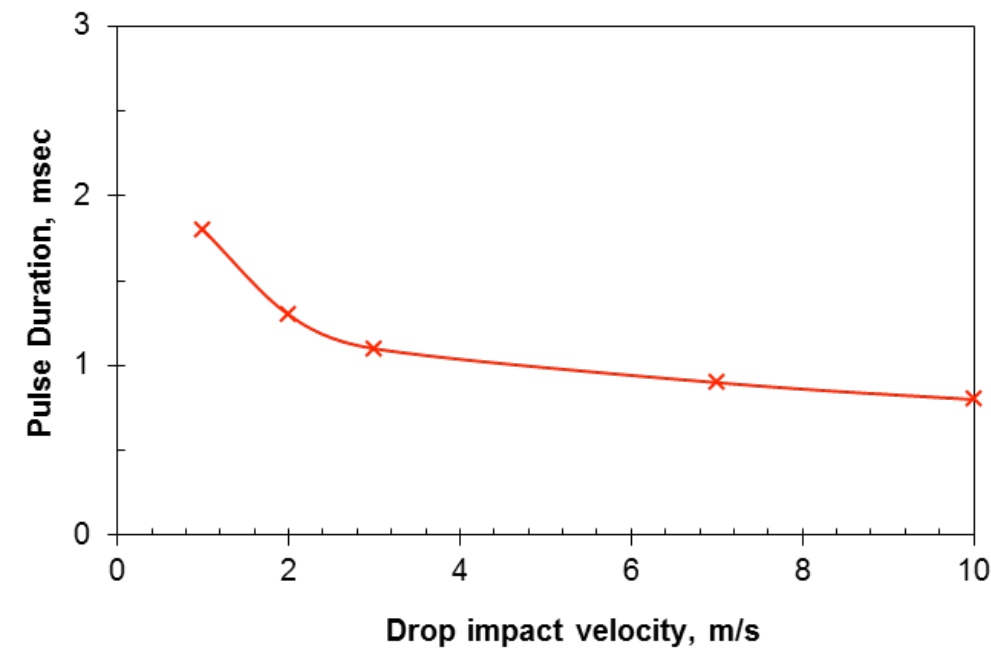

b) Pulse duration

Figure 8 Influence of drop impact velocity on axial forces of prestressing tendons 


\section{CONCLUSIONS}

The experimental and numerical simulations of prestressed concrete sleepers subjected to impact loading have been carried out in this paper. The three-dimensional finite element model have been established for investigate both static and dynamic behaviors of the railway sleepers. It has then been appended the track components to mimic in-situ conditions often found in actual tracks. A commercial finite element package, LS-Dyna, has been employed to extend the model for impact analysis and it has been validated against experimental drop impact tests. Nonlinear material properties under high strain rate effects were used. The emphasis of this study is placed on the dynamic responses of pre-stressing tendons inside the concrete sleeper. The further study on the effect of high train speeds and better nonlinear material models of track component degradation will be presented in the future. However, this paper firstly illustrates the influences of ballast moduli and drop impact velocity (simulating train speed effect) on the impact behavior of the pre-stressing tendons.

It is found that the ballast bed has an influence over the contact impact force characteristics including magnitude and duration. On the other hand, train speeds tend to play a role by generate high flexures of concrete sleepers as observed from the tension and compression.

\section{ACKNOWLEDGEMENT}

The first author would like to gratefully acknowledge the University of Birmingham's BRIDGE Grant, which financially supports this work as part of the project "Improving damping and dynamic resistance in concrete through micro- and nano-engineering for sustainable and environmental-friendly applications in railway and other civil construction". This project is part of a collaborative BRIDGE program between the University of Birmingham and the University of Illinois at Urbana Champaign. The pre-stressed concrete sleepers were kindly provided by Austrak Ltd. The authors would also like to thank Alan Grant, Ian Bridge, Bob Roland, and Jason Knurst, for their assistance during the course of the experimental work.

\section{REFERENCES}

[1] Kaewunruen, S and Remennikov, AM, Non-destructive testing (NDT): A tool for dynamic health monitoring of railway track structures. Materials Australia, 39(6), 14-16 (invited), 2006.

[2] Remennikov, A.M. and Kaewunruen, S., A review on loading conditions for railway track structures due to train and track vertical interaction. Structural Control and Health Monitoring, 15, 207-234, 2008.

[3] Murray, M and Cai, Z, Literature review on the design of railway prestressed concrete sleeper. RSTA Research Report, Australia, 1998.

[4] Kaewunruen, S and Remennikov, AM, "Experimental and numerical studies of railway prestressed concrete sleepers under static and impact loads." Civil Computing, AITACECOMS, inpress, 2007, (invited).

[5] Gustavson, R, "Static and dynamic finite element analyses of concrete sleepers", Licentiate of Engineering Thesis, Department of Structural Engineering, Chalmers University of Technology, Sweden, 2000. 
[6] Gustavson, R, "Structural behaviour of concrete railway sleepers", PhD Thesis, Department of Structural Engineering, Chalmers University of Technology, Sweden, 2002.

[7] Kaewunruen, S and Remennikov, AM, "Nonlinear finite element modelling of railway prestressed concrete sleeper", Proceedings of the tenth East Asia-Pacific Conference on Structural Engineering \& Construction (EASEC-10), Bangkok, Thailand, August 3-5, 2006, Vol. 4, pp. 323-328.

[8] Standards Australia, "Railway track material - Part 14: Prestressed concrete sleepers" Australian Standard: AS1085.14-2003, 2003a.

[9] Standards Australia, "Railway track material - Part 19: Resilient fastening assemblies" Australian Standard: AS1085.19-2003, 2003b.

[10] Livermore Software Technology Corporation, LS-DYNA theoretical manual. Livermore Software Technology Corporation, May 1998.

[11] Standards Australia, "Design of concrete structures" Australian Standard: AS3600-2001, 2001.

[12] Wakui $\mathrm{H}$ and Okuda H, "A study on limit-state design for prestressed concrete sleepers." Concrete Library of JSCE 33: pp. 1-25, 1999.

[13] Remennikov, AM and Kaewunruen, S, "Determination of dynamic properties of rail pads using instrumented hammer impact technique." Acoustics Australia, 33(2), 63-67, 2005.

[14] Remennikov, AM and Kaewunruen, S, "Experimental investigation on dynamic railway sleeper/ballast interaction." Experimental Mechanics, 46(1), 57-66, 2006.

[15] Kaewunruen, S and Remennikov, AM, "Sensitivity analysis of free vibration characteristics of an in-situ railway concrete sleeper to variations of rail pad parameters." Journal of Sound and Vibration, 298(1-2), 453-461, 2006.

[16] Kaewunruen, S and Remennikov, AM, "Effect of improper ballast tamping/packing on dynamic behaviors of on-track railway concrete sleeper." International Journal of Structural Stability and Dynamics, 7(1), 1-11, 2007.

[17] Kaewunruen, S and Remennikov, AM, "Post-failure mechanism and residual loadcarrying capacity of railway prestressed concrete sleeper under hogging moment", Proceedings of the International Conference on Structural Integrity and Failure (SIF-2006), Sydney, Australia, September 27-29, pp. 331-336, 2006.

[18] Remennikov, AM, Kaewunruen, S, and Ikaunieks, K, "Deterioration of dynamic rail pad characteristics." Proceedings of Conference of Railway Engineering 2006, Apr 30 May 3, Melbourne, Australia, pp.173-179, 2006.

[19] Kaewunruen, S and Remennikov, AM, "Monitoring structural degradation of rail bearing pads in laboratory using impact excitation technique." Proceedings of the 1st International Conference on Structural Condition Assessment, Monitoring, and Improvement, Dec 12-14, Perth, Australia, pp. 399-405, 2005.

[20] Kaewunruen, S. and Remennikov, A., 2007, "Low-velocity impact analysis of prestressed concrete sleepers." Concrete Institute of Australia's 23rd Biennial Conference 07, October 18-20, Adelaide, Australia, [CD Rom]. 